Twin-assisted precipitation during hot compression of an Mg-Gd-Zn-Zr magnesium alloy

Mohammad Saadati $^{\mathrm{a}}$, Rasoul Azari Khosroshahi ${ }^{\mathrm{a}, *}$, Golamreza Ebrahimi ${ }^{\mathrm{b}}$, Mohammad Jahazi ${ }^{\mathrm{c}, *}$

${ }^{a}$ Faculty of Materials Engineering, Sahand University of Technology, Tabriz, Iran

${ }^{b}$ Materials and Polymers Engineering Department, Faculty of Engineering, Hakim Sabzevari University, Sabzevar, Iran

c Département de Génie Mécanique, École de technologie supérieure, 1100 Notre-Dame Street West, Montreal, Canada H3C 1 K3

Authors' accepted manuscript

Article published in Materials Science and Engineering: A, vol. 706 (2017)

https://doi.org/10.1016/j.msea.2017.08.112

(c) 2017. Made available under the CC-BY-NC-ND 4.0 license

http://creativecommons.org/licenses/by-nc-nd/4.0/ 


\title{
Twin-assisted precipitation during hot compression of an Mg-Gd-Zn-Zr magnesium alloy
}

\author{
Mohammad Saadati a , Rasoul Azari Khosroshahi a, ${ }^{\text {,* }}$, Golamreza Ebrahimi ${ }^{\text {b }}$, Mohammad Jahazi ${ }^{\text {c,* }}$ \\ ${ }^{a}$ Faculty of Materials Engineering, Sahand University of Technology, Tabriz, Iran \\ ${ }^{b}$ Materials and Polymers Engineering Department, Faculty of Engineering, Hakim Sabzevari University, Sabzevar, Iran \\ ${ }^{c}$ Département de Génie Mécanique, École de technologie supérieure, 1100 Notre-Dame Street West, Montreal, H3C 1K3, Canada
}

\begin{abstract}
Dynamic precipitation in an $\mathrm{Mg}-\mathrm{Gd}-\mathrm{Zn}-\mathrm{Zr}$ alloy during hot compression at $350^{\circ} \mathrm{C}$ and $450^{\circ} \mathrm{C}$ and at strain rates of $0.001-0.1 \mathrm{~s}^{-1}$ is investigated. The deformation conditions were designed such as to promote twinning or slip of dislocations. The results indicated that both twinned and non-twinned grains were present at $350^{\circ} \mathrm{C}$, with the extent being a function of the applied strain rate. The formation and propagation of $\{10 \overline{1} 2\}\langle\overline{1} 011\rangle$ primary tensile twins within the twinned grains was identified as being at root of the twin-assisted precipitation phenomenon. The precipitates had spherical-morphology in the twinned grains whereas parallel arrays of rod-shaped precipitates formed in the non-twinned grains due to dynamic precipitation on the slip bands and the stacking faults. Twin-assisted precipitates were suppressed by increases in the strain rate at $350^{\circ} \mathrm{C}$ because of the shorter time required for solute element diffusion towards the nucleated precipitates at that temperature. Increasing the deformation temperature to $450^{\circ} \mathrm{C}$ changed the dominant deformation
\end{abstract}

\footnotetext{
* Corresponding author. Département de Génie Mécanique, École de technologie supérieure, 1100 Notre-Dame Street West, Montreal, H3C 1K3, Canada

E-mail address: mohammad.jahazi@etsmtl.ca (M. Jahazi), Tel: +1 514 396-8974

*** Corresponding author. Faculty of Materials Engineering, Sahand University of Technology, Tabriz, Iran

E-mail address: rakhosroshahi@sut.ac.ir (R. Azari Khosroshahi) 
mechanism from twinning to slip of dislocations, resulting in the formation of rod-shaped precipitates similar to those observed in non-twinned grains at $350^{\circ} \mathrm{C}$. An EBSD analysis was used to study the dominant deformation mechanism as a function of the Schmid factor, and the twinning deformation mechanism was found to be predominant in the grains having a lower Schmid factor.

Keywords: Twin-assisted precipitation, hot compression, precipitate morphology, Schmid factor, LPSO structure

\section{Introduction}

Twinning is one of the main deformation mechanisms present in magnesium alloys, especially at low temperatures, due mainly to the limited number of active slip systems characterizing the hexagonal close packed (hcp) structure. Among hcp materials, magnesium manifests a special behavior as twins can spread over the entire matrix even with strain levels as low as $7 \%$ [1]. Depending on the loading direction with respect to the c-axis of the hcp structure, deformation twins can be classified as tensile, contraction or double twins (a combination of tensile and contraction twins) [2]. The main twinning system present during hot compression of $\mathrm{Mg}$ alloys has been identified as being the $\{10 \overline{1} 2\}\langle\overline{1} 011\rangle$ tensile twinning system [3]. However, $\{10 \overline{1} 1\}\langle\overline{1} 012\rangle$ and $\{10 \overline{1} 3\}\langle\overline{3} 032\rangle$ twinning systems have also been observed at larger strains $[3$, $4]$.

It is well accepted that twinning is a nucleation and growth process [5-7]. Studies that have looked at the onset of twinning have determined that deformation via slipping is a precondition for the initiation of twin nucleation [1]. Furthermore, numerous mechanisms [8-11] have been proposed on twin nucleation and growth, and these rely on the formation of twinning dislocations (TDs). In a recent study, Wang et al. [10] reported that the nucleus of a twin contains multiple-unit TDs as 
well as TDs in opposite sign. Therefore, the growth of twins, which occurs by twin boundary migration in the longitudinal and transverse directions, is highly dependent on the ease of TD movements. As the latter occurs by consecutive glide shuffle on the twin plane [10], all the interactions that take place between slip system dislocations and matrix imperfections are therefore also expected for twin boundary dislocations.

In addition to the effects of twinning on the resulting texture and workability of the alloy $[12,13]$, twinning influence also the precipitation behavior. Numerous studies have been reported on the interactions between twins and pre-existing precipitates within the matrix, and phenomena such as impingement, bypassing or engulfment of precipitates have been observed [14-16]. However, few studies have examined the effect of twinning on precipitate formation during deformation $[14,17$, 18]. Precipitation has been observed on twin boundaries as well as in the interior of twins [4, 14]. Grain boundaries, twin boundaries, stacking faults and slip bands are considered to be the heterogeneous nucleation sites for precipitation in magnesium alloys. Among these, next to grain boundaries, twin boundaries are considered to be the most favorable sites for nucleation of precipitates [17]. Precipitation on stacking faults and slip bands or on twin boundaries greatly depends on the energy of these lattice imperfections, the magnitude of the imposed strains, and the coherency of the twin boundary with the matrix [17]. However, to the knowledge of the authors, the role of deformation twins on dynamic precipitation and particularly the relation between grain orientation and precipitation tendency on deformation twins has not been investigated. The aim of the present research is to study such interactions in an $\mathrm{Mg}-3.5 \mathrm{Gd}-1 \mathrm{Zn}-0.6 \mathrm{Zr}$ alloy under hot compression deformation at different strain rates and temperatures. Specifically, twin formation, evolution and interactions with other matrix imperfections such as stacking faults, long-period 
stacking ordered (LPSO) structures and other imperfections are investigated, and a new mechanism for twin-assisted precipitation (TAP) is proposed.

\section{Materials and experimental procedure}

In order to achieve the targeted composition of $\mathrm{Mg}-3.5 \mathrm{Gd}-1 \mathrm{Zn}-0.6 \mathrm{Zr}$ (wt\%) alloy, pure $\mathrm{Mg}$ and $\mathrm{Zn}$ were melted together with $\mathrm{Mg}-10 \mathrm{Gd}$ and $\mathrm{Mg}-5 \mathrm{Zr}$ master alloys in an electric resistance furnace at $750^{\circ} \mathrm{C}$ under $\mathrm{CO}_{2}$ protective atmosphere. The molten alloy was cooled down to $715^{\circ} \mathrm{C}$, and poured into a preheated steel mold, which was also protected by $\mathrm{CO}_{2}$ atmosphere. The alloy was then homogenized and extruded using an extrusion ratio of 8.5:1 to reach a final diameter of $12 \mathrm{~mm}$. Hot compression specimens $(12 \mathrm{~mm}$ length $\times 8 \mathrm{~mm}$ diameter $)$ were the prepared from the extruded rod and solutionized for $3 \mathrm{hr}$ at $540^{\circ} \mathrm{C}$, followed by water quenching. For uniaxial hot compression tests, samples were heated to deformation temperatures of $350^{\circ} \mathrm{C}$ and $450^{\circ} \mathrm{C}$, soaked for 5 min, and then deformed to a strain of 0.76 at $0.001 \mathrm{~s}^{-1}, 0.01 \mathrm{~s}^{-1}$ and $0.1 \mathrm{~s}^{-1}$ strain rates, immediately followed by water quenching. A Zwick-Roell Z250 testing instrument was used for hot compression testing; temperature measurement was carried out using K-type thermocouples, and all the tests were conducted under pure Argon protective atmosphere. The results obtained were validated by random repetition of some experiments.

For the purpose of microstructural examinations, the specimens were cut parallel to the compression direction, polished using standard metallography techniques, and etched by $4 \%$ Nital solution for $30 \mathrm{~s}$. Optical and scanning electron microscopy (SEM) observations were performed using LEXT OLS4100 laser confocal microscope and a Hitachi SU-8230 Field Emission-STEM, respectively. An Electron BackScatter Diffraction (EBSD) study was carried out after a fine polishing using a Hitachi IM3000 flat milling system in order to obtain high image quality. Further 
phase characterizations were carried out by X-ray diffraction using a PANalytical X-ray diffractometer with $\mathrm{Cu} \mathrm{K}_{\alpha}$ radiation.

\section{Results}

\subsection{Initial microstructure}

The microstructure of the solutionized $\mathrm{Mg}-3.5 \mathrm{Gd}-1 \mathrm{Zn}-0.6 \mathrm{Zr}$ alloy is shown in Fig. 1. This microstructure, used as a reference in the rest of the study, is composed of $\alpha-\mathrm{Mg}$ matrix with equiaxed grains of about $\sim 115 \mu \mathrm{m}$ and blocky-shaped particles of the $\mathrm{MgGd}_{3}$ phase. These particles (Fig. 1a) appear to be remnants from the extrusion process that were not dissolved during solutionizing treatment. The chemical compositions of the particle and the matrix in Fig. 1b were characterized by EDS, and are presented in Figs. 1c and 1d, respectively. The presence of Mg and Gd is clearly illustrated in the blocky shaped particles as also reported by other authors [19]. Fig. 2 shows the microstructures of the specimens after solutionizing and isothermal holding for $5 \mathrm{~min}$ at deformation temperatures, i.e., $350^{\circ} \mathrm{C}$ and $450^{\circ} \mathrm{C}$. It can be seen that both microstructures are precipitate-free after 5 min of holding and before the application of deformation.

\subsection{Flow behavior at $350^{\circ} \mathrm{C}$ and $450^{\circ} \mathrm{C}$}

The true stress-true strain curves of the solutionized alloy after hot compression at $350^{\circ} \mathrm{C}$ and $450^{\circ} \mathrm{C}$ with strain rates of $0.001 \mathrm{~s}^{-1}$ to $0.1 \mathrm{~s}^{-1}$ are shown in Fig. 3. A significant dependence of the flow behavior on the deformation temperature can be seen. At $350^{\circ} \mathrm{C}$ (Fig. 3a), the flow stress reaches a peak value, and then decreases sharply due to intense shearing, and ultimately, cracking of the specimen. A concave curvature in the flow curves, pointed by the arrow in Fig. 3a, was observed for all tested strain rates. Mu, Jonas and Gottestien [20] carried out a detailed analysis of the concave curvature in the stress-strain curve of $\mathrm{Mg}$ alloys, and related its presence to conditions 
where the dominant deformation mechanism is twinning. Similar findings have also been reported by other researchers [21-25]. Consequently, it can reasonably be stated that under certain thermomechanical treatment conditions, twinning could also be the dominant deformation mechanism in the investigated $\mathrm{Mg}-3.5 \mathrm{Gd}-1 \mathrm{Zn}-0.6 \mathrm{Zr}$ alloy.

The flow curves of the hot compressed specimens at $450^{\circ} \mathrm{C}$ are shown in Fig. 3b. In contrast to the tests at $350^{\circ} \mathrm{C}$, the concave curvature is only present for the highest strain rate (i.e., $0.1 \mathrm{~s}^{-1}$ ). Also, a comparison between the flow curves at $350^{\circ} \mathrm{C}$ (Fig. 3a) and $450^{\circ} \mathrm{C}$ (Fig. 3b) shows that an increase in the deformation temperature leads to an abrupt decrease in the flow stress level (of over 53\%) and to a significant increase in elongation (over 21\%) as a result of a gradual change in the deformation mechanism from twinning to dislocation slip.

\subsection{As-deformed microstructures at $350^{\circ} \mathrm{C}$}

In order to determine the type of phases present within the microstructure, the XRD method was employed. The diffractograms for the deformed specimens at both investigated temperatures and at a $10^{-3} \mathrm{~s}^{-1}$ strain rate are shown in Fig. 4. An examination of the diffractograms reveals the presence of $(\mathrm{Mg}, \mathrm{Zn})_{3} \mathrm{Gd}$ phase and an LPSO structure at both temperatures. A microstructure of the alloy after hot compression at $350^{\circ} \mathrm{C}$ and at a $0.001 \mathrm{~s}^{-1}$ strain rate is shown in Fig. 5. The low ductility of the alloy under these testing conditions, as reported in Fig. 3a, indicates that the deformation proceeds mostly by the formation of twins. However, as shown in Fig. 5a, both twinned and non-twinned grains are visible. The non-twinned grains contribute to the deformation mostly by dislocation glide, and are in contrast to twinned grains, which contain profuse twinning in different directions with widths larger than $\sim 1 \mu \mathrm{m}$. The morphology of the observed twins is lentoid-shaped (inset of Fig. 5a), confirming that they are deformation twins, as is also observed for other magnesium alloys [26, 27]. 
Fig. $5 \mathrm{~b}$ shows the presence of precipitates within the non-twinned grains that are arranged in parallel lines. Since the starting material was in the supersaturated solid solution (SSS) state, and the deformation temperatures $\left(350^{\circ} \mathrm{C}\right.$ and $\left.450^{\circ} \mathrm{C}\right)$ were well below the solutionizing temperature $\left(540^{\circ} \mathrm{C}\right)$, the presence of precipitates after deformation at $350^{\circ} \mathrm{C}$ can only be correlated to the effect of deformation, i.e., a dynamic precipitation (DIP) of $(\mathrm{Mg}, \mathrm{Zn})_{3} \mathrm{Gd}$ particles has taken place. However, precipitation in the twinned grain is quite different. The mutual interactions between DIP and twin propagation can be seen from the overlying of the precipitated zone and twinning. Fig. 5c shows a twinned grain, which contains some parallel arrays of precipitates in the parent regions that are denoted by arrows. SEM observations (Fig. 5d) revealed that these parallel arrays of precipitates crossed the twins without any change in their alignment. This indicates that these parallel rows of precipitates formed before the development of twins, and result from the effect of the compressive load on precipitation from solute-enriched stacking faults [28].

It is worth noting that the morphologies of the precipitates present in the twinned and non-twinned grains are very different. A comparison of the dynamic precipitation in the twinned and nontwinned grains (Fig. 6) indicates that fine rod-shaped precipitates have formed in parallel arrays within the non-twinned grains, while in the twinned grains, larger size spherical shaped precipitates randomly distributed in the matrix are produced. An illustrative example of these grains is presented in Fig. 6a, where a grain boundary containing larger spherical shape precipitates has separated a twinned grain with a smaller amount of precipitates (upper region in Fig. 6a) from a non-twinned grain (lower region in Fig. 6a) containing abundant parallel-arranged rod-shaped precipitates. A particle size measurement indicated that the rod-shaped precipitates shown in Fig. $6 \mathrm{~b}$ are less than $150 \mathrm{~nm}$ in length. In contrast, as shown in Figs. $6 \mathrm{c}$ and $6 \mathrm{~d}$, the average diameter of 
the spherical precipitates is about $15 \mathrm{~nm}$, and they are randomly distributed, just like the grain boundary precipitates in Fig. 6a.

The orientation of the grains with respect to the loading direction was characterized using the EBSD inverse pole figure (IPF) analysis, and the results are shown in Fig. 7a. The corresponding Schmid factor values for the $\{0001\}\langle 11 \overline{2} 0\rangle$ basal slip system is presented in Fig. 7b. An examination of the results reveals that the Schmid factors of the non-twinned grains (A ( 0.39) and B ( 0.44)), are significantly higher than those for parent regions of twinned grains $(\mathrm{C}(\sim 0.025)$ and D ( 0.065)). Therefore, the A and B non-twinned grains can reach the critical resolved shear stress (CRSS) to activate the dislocation glide on the $\{0001\}\langle 11 \overline{2} 0\rangle$ basal slip system [29] more easily than the grains with very low Schmid factor values (C and D). Fig. 7c shows the EBSD analysis of twinned grain $\mathrm{C}$ of Fig. 7a. The misorientation distributions for the total area, subset 1 and subset 2 in Fig. 7c, are illustrated in Fig. 7d; these misorientations reveal 4 main peaks at about $5^{\circ}, 36^{\circ}, 58^{\circ}$ and $86^{\circ}$. A subdivision of the total misorientation into subsets 1 and 2 presents the corresponding origins of these peaks. Subset 1 , with a misorientation angle of about $86^{\circ} \pm 5$, is characteristic of the $\{10 \overline{1} 2\}<10 \overline{1} 1>$ tensile twins, and subset 2 , with a misorientation angle of about $36^{\circ} \pm 5$, is characteristic of the double twinning.

The effect of increasing the strain rate from $0.001 \mathrm{~s}^{-1}$ to $0.01 \mathrm{~s}^{-1}$, and then to $0.1 \mathrm{~s}^{-1}$ on precipitation at $350^{\circ} \mathrm{C}$ is illustrated in Fig. 8. Specifically, in Figs. 8a and 8c, the characteristics of the precipitates related to the $0.01 \mathrm{~s}^{-1}$ and $0.1 \mathrm{~s}^{-1}$ strain rates are reported. The results indicate that precipitates in the twinned regions of the matrix are much smaller in size as compared to the grain boundary precipitates (Fig. 8a). As described in Figs. $6 \mathrm{c}$ and $6 \mathrm{~d}$ for the $0.001 \mathrm{~s}^{-1}$ strain rate, these are due to dynamic precipitation. The magnified micrographs of Figs. $8 \mathrm{a}$ and $8 \mathrm{c}$ are presented in 
Figs. $8 \mathrm{~b}$ and $8 \mathrm{~d}$, respectively. It is clear that the precipitates are spherical in shape, and that their average size decreases as the strain rate increases.

\subsection{As-deformed microstructures at $450^{\circ} \mathrm{C}$}

Microstructures of the alloy deformed at $450^{\circ} \mathrm{C}$ and at $0.001 \mathrm{~s}^{-1}$ strain rate are shown in Fig. 9a, where it can be seen that both dynamic recrystallization and precipitation have taken place at this temperature. The initial grain boundaries can be identified as they are decorated by $(\mathrm{Mg}, \mathrm{Zn})_{3} \mathrm{Gd}$ particles. Fig. 9b shows the intra-granular rod-shaped precipitates, which are along parallel lines. These precipitates have an average length of about $2 \mu \mathrm{m}$, i.e., they are one order of magnitude larger than those observed at $350^{\circ} \mathrm{C}$. Their chemical composition is presented in Fig. 9c. Figure 10a shows the TEM image of the deformed alloy at $450^{\circ} \mathrm{C}$ and at $0.001 \mathrm{~s}^{-1}$ strain rate. The black parallel lines are the stacking faults with the $(\mathrm{Mg}, \mathrm{Zn})_{3} \mathrm{Gd}$ precipitates which are aligned with them. The HRTEM investigation of the matrix (Fig. 10b), revealed the presence of a 14H-LPSO structure in the matrix.

Increasing the strain rate to $0.01 \mathrm{~s}^{-1}$, and then to $0.1 \mathrm{~s}^{-1}$ at $450^{\circ} \mathrm{C}$, results in the formation of rodshaped dynamically precipitated particles for both strain rates (Fig. 11). Randomly oriented grain boundary precipitates, as well as parallel arrays of intra-granular precipitates, were observed for both strain rates. A comparison of Figs. $11 \mathrm{~b}$ and $11 \mathrm{~d}$ shows that while the precipitates are still formed in continuous arrays, their length has decreased as the strain rate increases. The formation of deformation twins within the initial grains at $0.1 \mathrm{~s}^{-1}$ strain rate can be observed in Fig. 11c. This finding is in agreement with the observed concavity in the stress-strain curve at this strain rate in Fig. 3b, and confirms that the observed concavity in the stress-strain curves of the Mg alloys can be reliably correlated to the occurrence of deformation twins [30]. The change in the alignment of 
precipitates at twin boundaries (formation of step-like arrangements pointed by arrows in Fig. 11c) indicates that the precipitates were formed after twinning occurred.

\section{Discussion}

\subsection{Effect of grain orientation on precipitation behavior}

Microstructural investigations of the deformed $\mathrm{Mg}-3.5 \mathrm{Gd}-1 \mathrm{Zn}-0.6 \mathrm{Zr}$ alloy at $350^{\circ} \mathrm{C}$ and $450^{\circ} \mathrm{C}$ and at different strain rates show that dynamic precipitation of $(\mathrm{Mg}, \mathrm{Zn})_{3} \mathrm{Gd}$ particles occurred for all deformation conditions. However, the morphology, size, distribution and volume fraction of the precipitates depend greatly on the operating deformation mechanism and the strain rate.

At early stages of compression, all the grains deform by slip of dislocations. However, further deformation could occur either by slipping or twinning, depending on the Schmid factor of the grains, and consequently, on the critical resolved shear stress $\left(\tau_{C R S S}\right)$ of slip systems and twins. EBSD results reported in Figs. $7 \mathrm{a}$ and $7 \mathrm{~b}$ confirm that at $350^{\circ} \mathrm{C}$, for grains with high Schmid factors, the main deformation mechanism was the slip of dislocations, while for those with low

Schmid factors, it was twinning. Therefore, two types of grains were observed, namely, twinnedand non-twinned grains. The results reported in Figs. $6 \mathrm{a}$ and $6 \mathrm{~b}$ show that at $350^{\circ} \mathrm{C}$, dynamic precipitation took place in the form of rod-shaped precipitate arrays in non-twinned grains with high Schmid factors. This precipitation behavior originated from deformation by slip of dislocations in non-twinned grains. In a previous study [28], the authors showed that while two LPSO and $(\mathrm{Mg}, \mathrm{Zn})_{3} \mathrm{Gd}$ phases coexist in the $\mathrm{Mg}$ matrix, dissolving the $(\mathrm{Mg}, \mathrm{Zn})_{3} \mathrm{Gd}$ phase during solutionizing leads to an excess formation of the LPSO structure. Also, it was shown that below the dissolution temperature of the $(\mathrm{Mg}, \mathrm{Zn})_{3} \mathrm{Gd}$ phase, applying compressive loads could result in the decomposition of the LPSO structure and the precipitation of the $(\mathrm{Mg}, \mathrm{Zn})_{3} \mathrm{Gd}$ phase. 
Accordingly, precipitation in non-twinned grains under compressive load deformed by slip of dislocations occurred on stacking faults of the LPSO structure and slip planes.

Precipitation under the same mechanism was also observed at $450^{\circ} \mathrm{C}$, where the dominant deformation mechanism was slip of dislocations due to the CRSS of the slip systems decreasing with increasing temperature. However, in the case of twinned grains at $350^{\circ} \mathrm{C}$, the precipitation pattern follows more complicated steps. Firstly, it should be noted that the deformation mechanism is a combination of slip and twinning in these grains. According to Yoo et al. [5], an initial deformation, controlled by slip, is necessary for the nucleation of twins. In the present study, deformation by slip of dislocations before nucleation of twins at the initial stages of hot compression at $350^{\circ} \mathrm{C}$ resulted in the dynamic precipitation in parallel rows on stacking faults. In a previous study [28], the authors also observed dynamic precipitation on some deformation slip planes. The above findings can be related to the effect of compressive load on the decomposition of solute-enriched stacking faults to the $(\mathrm{Mg}, \mathrm{Zn})_{3} \mathrm{Gd}$ precipitates. Such a precipitation line-up is shown in Figs. 5c and 5d. Further deformation after the initial slipping stage promotes the formation of twins due to insufficient active slip systems available. The straightness of the precipitation lines in the parent and twinned regions in Fig. 5d reveals that dynamic precipitation has occurred before twinning. Otherwise, as has been observed for the static precipitation of a similar alloy in a twinned matrix [28], the precipitate line should be broken at twin boundaries.

\subsection{Twin boundary characteristics and precipitation}

Figs. $6 \mathrm{c}$ and $6 \mathrm{~d}$ show that precipitation is accelerated in twinned regions with respect to the parent lattice. This finding could be analyzed in terms of the differences in lattice characteristics around slip dislocations and twin boundary dislocations. Indeed, it should be noted that twin boundaries consist of dislocations [8-11], and that the growth of the twin (both lengthwise and widthwise) 
depends on the twin boundary dislocation motion. Similarly to dislocations in a slip system, twin boundary dislocations are expected to have interactions and junctions with other barriers and lattice imperfections, which are potential sites for dynamic precipitation, such as lattice dislocations, vacancies and especially, stacking faults and slip bands [31,32]. However, the main difference between a slip system dislocation and a twin boundary dislocation lies in how they interact with the surrounding lattice at their junction with an imperfection. The presence of a lattice misfit region around a twin [9] at the intersection of the twin boundary dislocation and an imperfection, e.g., a stacking fault, increases the lattice perturbation, thereby providing a suitable nucleation site for precipitates. Accordingly, twin boundaries are reported to be high diffusivity paths, even for coherent twin boundaries [33, 34]. In other words, the formation of twins accelerates the precipitation in a dynamic manner, i.e., twin-assisted precipitation (TAP).

The twin-assisted precipitation mechanism can also be analyzed from a thermodynamic perspective. It is well accepted that the Gibbs free energy change as a result of the formation of precipitates in the matrix depends on the interfacial energy and elastic strain energy between the second phase and the matrix, as follows:

$\Delta G=-V_{p}\left(\Delta G_{v}-\Delta G_{s}\right)+A_{p} \gamma$

where $V_{p}$ and $A_{p}$ are the volume and the surface area of the nucleated precipitate, respectively; $\Delta G_{v}$ is the energy change by the formation of a unit volume of the precipitate; $\Delta G_{s}$ is the elastic strain energy due to the formation of precipitate, and $\gamma$ is the interfacial energy generated as a result of the new surface created between the precipitate and the matrix. It can be deduced from Eq.1 that precipitation can be increased when the Gibbs free energy is minimized, thereby decreasing the elastic strain energy $\Delta G_{s}$ and/or interfacial energy $\gamma$. 
The nucleation of a precipitate in a lattice is accompanied by the generation of misfit dislocations around it, depending on the coherency of their interface [35]. The elastic strain energy $\Delta G_{s}$ is composed of the sum of the elastic self-energy $E_{\text {self }}$ of the matrix and particle, and of the elastic interaction energy $E_{\text {interaction }}$ between the precipitate and the misfit dislocations [36]. This means that the pure elastic energies imposed on both the matrix and particle can be accommodated by the misfit dislocations, if the latter are available. Therefore, the presence of some pre-existing misfit regions (e.g., regions adjacent to twin boundary dislocations) related to the misfit dislocations should promote the heterogeneous nucleation of precipitates. As reported by Bishop [37], the boundary of two lattices is a misfit region and the boundary angle can be determined by the fraction of coincidence sites, i.e., the fraction of lattice sites which are common between two lattices. The lower the number of coincidence sites, the higher the number of misfit regions [38]. This observation can also be realized from the calculated increase in energies of the system due to the formation of different boundaries in Magnesium. The twin boundary energy calculated for different twinning systems in $\mathrm{Mg}$ has been reported to be $114-188 \mathrm{~mJ} / \mathrm{m}^{2}[39,40]$ for $\{10 \overline{1} 2\}$ tensile twins, $70-142 \mathrm{~mJ} / \mathrm{m}^{2}[39,40]$ for $\{10 \overline{1} 1\}, 145-186 \mathrm{~mJ} / \mathrm{m}^{2}$ for $\{11 \overline{2} 2\}$, and $147 \mathrm{~mJ} / \mathrm{m}^{2}$ for $\{11 \overline{2} 1\}$ contraction twins [40]. These energies, which are associated with the formation of lattice misfit regions and a decrease in the fraction of coincidence sites, are almost in the range of the grain boundary energy $\left(100 \mathrm{~mJ} / \mathrm{m}^{2}\right)[41]$, and are higher by an order of magnitude than the SFE for the I1 $\left(4-39 \mathrm{~mJ} / \mathrm{m}^{2}\right.$ [39]) and for I2 $\left(8-38 \mathrm{~mJ} / \mathrm{m}^{2}\right.$ [39]) stacking faults. Therefore, it can be concluded that the heterogeneous nucleation of precipitates on magnesium twin boundaries and grain boundaries is favored over the stacking faults and grain interior because the misfit energy $\Delta G_{s}$ generated as a result of precipitate formation decreases due to the higher misfit regions at twin boundaries and grain boundaries. 
Similarly to the dynamic recrystallization and deformation-induced precipitation mechanisms in which recrystallization or precipitation occurs during deformation, the twin-assisted precipitation mechanism is associated with the occurrence of precipitation during twinning. It is worth mentioning that, as shown in Figs. 6c, 8a and 8c, such precipitation does not occur in the nontwinned regions.

\subsection{Effect of twinning on precipitate morphology}

It can be seen in Figs. $6 \mathrm{c}$ and $6 \mathrm{~d}$ that precipitates in the twinned regions have a spherical shape, versus the rod-shaped ones observed in non-twinned grains (Figs. 6a and 6b). As discussed earlier, the spherical precipitates in the twinned regions are the nucleated precipitates at twin boundaries (TBs) which are left behind within the twinned region while the twinned region is growing. This difference in the precipitate morphology could also be due to the presence of the lattice misfit region at twin boundaries, which helps reduce the elastic strain energy due to the formation of precipitates. As stated by Nabarro [42], the morphology and the aspect ratio of precipitates are influenced by the elastic strain energy of the surrounding matrix, and vary from spherical- to rodor plate-shaped morphologies, according to the Nabarro's equation [43]:

$\Delta G_{s}=(2 / 3) \mu_{m} \Delta^{2} f$

where $\Delta$ and $\mu_{M}$ are the volume misfit and shear modulus of the matrix, respectively, and $f$ is the Laue interference function, which is a factor showing the precipitate shape effects. Although spherical precipitates have the minimum surface area, and therefore, the second term in Eq.1 will be minimized for them, the value of $f$, and hence, the elastic strain energy, is at its highest [43]. Since the lattice in the twin boundary region is distorted, the lattice coincidence sites are decreased, and the lattice atoms are relocated by a multiple factor of the interatomic distance of the perfect 
lattice [44]; Therefore, the elastic strain energy generated by the formation of a new precipitate at twin boundaries will be lower compared to what is seen at the regions away from it. This situation provides an opportunity to form spherical precipitates to decrease their surface energy.

Conversely, in order to compensate the high elastic energy in the grain interior, precipitates must adopt a rod-shaped morphology in order to decrease the elastic strain energy according to Eq. 2. A comparison of the morphology of the twin boundary precipitates in Fig. 6d with the grain boundary precipitates in Fig. 6a, shows that both are spherical in shape, thereby confirming a good agreement with the above analysis. Similar morphology variations have also been reported by Jiang et al. [45], who observed both rod-shaped and spherical-shaped $\mathrm{MgZn}_{2}$ precipitate morphologies in Mg-Zn-Mn alloys. It is worth noting that the spherical precipitates inside twins are formed simultaneously with the boundary migration of tensile twins through the parent matrix. The misorientation angle of twins determined for subset 1 in Fig. 7c, and presented in Fig. 7d, confirms that the twins are primary tensile, with a misorientation angle of about $86^{\circ}$.

In summary, the proposed sequence of events for the formation of precipitates following the application of deformation is represented schematically in Figs. 12a to 12d: (a) At the initial state, the precipitate-free matrix of $\alpha-\mathrm{Mg}$ is in the super saturated solid solution state, and contains individual stacking faults and an LPSO structure, both enriched in $\mathrm{Zn}, \mathrm{Gd}$ and $\mathrm{Zr}$ solute elements [28]. (b) At early stages of hot compression $\left(\varepsilon_{1}\right)$, the compressive load makes the stacking faults unstable and also activates the dislocation glide on slip systems. Consequently, a $(\mathrm{Mg}, \mathrm{Zn})_{3} \mathrm{Gd}$ precipitation occurs on some stacking faults and slip bands all over the grains. (c) With an increase in the strain $\left(\varepsilon_{2}>\varepsilon_{1}\right)$, further deformation occurs via the twinning mechanism in grains with low Schmid factors (Grain I in Fig. 12c), while the high Schmid factor grains (Grain II in Fig. 12c) deform by the slip mechanism. Accordingly, spherical-shaped dynamic precipitation in the 
twinned grains (grain I) occurs at twin boundaries, whereas rod-shaped precipitation forms on slip bands and on the stacking faults of non-twinned grains (grain II). (d) Further deformation $\left(\varepsilon_{3}>\right.$ $\left.\varepsilon_{2}\right)$ results in the growth of twins simultaneously with dynamic precipitation on moving twin boundaries.

\section{Conclusions}

A hot compression of $\mathrm{Mg}-3.5 \mathrm{Gd}-1 \mathrm{Zn}-0.6 \mathrm{Zr}$ alloy was performed at the supersaturated solid solution state at $350^{\circ} \mathrm{C}$ and $450^{\circ} \mathrm{C}$ and at $0.001-0.1 \mathrm{~s}^{-1}$ strain rates. Different precipitation behaviors were observed during deformation at the studied temperatures. The main conclusions of the present investigation are as follows:

1. At initial stages of deformation at $350^{\circ} \mathrm{C}$, deformation started with the activation of some basal slip systems, and dynamic precipitation took place in rows associated with stacking faults and slip bands.

2. Increasing the strain leads to twin formation in some grains, which in turn divided the grains into twinned and non-twinned components, according to their Schmid factors. It was seen that precipitation occurred in both cases, but with different mechanisms and precipitate morphologies.

3. In non-twinned grains with higher Schmid factors, i.e., grains with appropriate orientations with respect to the compressive load, the deformation mechanism glided on active slip systems. Dynamic precipitation was observed in such grains in the form of rod-shaped precipitates in parallel arrays. 
4. In the case of twinned grains, the precipitates were observed inside twins with a spherical morphology. Their formation was discussed in terms of a twin-assisted precipitation (TAP) process on moving twin boundaries.

\section{References:}

[1] A. Moitra, S.-G. Kim, M. Horstemeyer, Solute effect on basal and prismatic slip systems of Mg, Journal of Physics: Condensed Matter 26(44) (2014) 445004.

[2] E.I. Galindo-Nava, P.E.J. Rivera-Díaz-del-Castillo, Thermostastitical modelling of deformation twinning in HCP metals, International Journal of Plasticity 55 (2014) 25-42.

[3] J.F. Nie, Y.M. Zhu, J.Z. Liu, X.Y. Fang, Periodic segregation of solute atoms in fully coherent twin boundaries, Science 340(6135) (2013) 957-60.

[4] X. Hou, Z. Cao, X. Sun, L. Wang, L. Wang, Twinning and dynamic precipitation upon hot compression of a Mg-Gd-Y-Nd-Zr alloy, Journal of Alloys and Compounds 525(0) (2012) 103-109.

[5] M. Yoo, J. Lee, Deformation twinning in hcp metals and alloys, Philosophical Magazine A 63(5) (1991) 987-1000.

[6] J. Tu, S. Zhang, On the twinning growth mechanism in hexagonal close-packed metals, Materials \& Design 96 (2016) 143-149.

[7] H.A. Khater, A. Serra, R.C. Pond, Atomic shearing and shuffling accompanying the motion of twinning disconnections in Zirconium, Philosophical Magazine 93(10-12) (2013) 1279-1298.

[8] J. Wang, R.G. Hoagland, J.P. Hirth, L. Capolungo, I.J. Beyerlein, C.N. Tomé, Nucleation of a twin in hexagonal close-packed crystals, Scripta Materialia 61(9) (2009) 903-906.

[9] S. Mendelson, Zonal dislocations and twin lamellae in h.c.p. metals, Materials Science and Engineering 4(4) (1969) 231-242.

[10] J. Wang, Q. Yu, Y. Jiang, I.J. Beyerlein, Twinning-Associated Boundaries in Hexagonal Close-Packed Metals, JOM 66(1) (2014) 95-101.

[11] J. Wang, J.P. Hirth, C.N. Tomé, Twinning nucleation mechanisms in hexagonal-close-packed crystals, Acta Materialia 57(18) (2009) 5521-5530.

[12] L. Jiang, J. Jonas, R. Mishra, A. Luo, A. Sachdev, S. Godet, Twinning and texture development in two Mg alloys subjected to loading along three different strain paths, Acta Materialia 55(11) (2007) 3899-3910.

[13] M.R. Barnett, Twinning and the ductility of magnesium alloys, Materials Science and Engineering: A 464(1-2) (2007) 1-7.

[14] Y. Zhang, T. Liu, X. Ding, S. Xu, J. He, H. Chen, F. Pan, L. Lu, The precipitation behavior of a pretwinned Mg-6Al-1Zn alloy and the effect on subsequent deformation, Journal of Materials Research 29(18) (2014) 2141-2146.

[15] J.D. Robson, N. Stanford, M.R. Barnett, Effect of precipitate shape on slip and twinning in magnesium alloys, Acta Materialia 59(5) (2011) 1945-1956.

[16] J. Wang, N. Stanford, Investigation of precipitate hardening of slip and twinning in Mg5\%Zn by micropillar compression, Acta Materialia 100 (2015) 53-63.

[17] N. Terao, B. Sasmal, Precipitation of M23C6 type carbide on twin boundaries in austenitic stainless steels, Metallography 13(2) (1980) 117-133.

[18] P. Changizian, A. Zarei-Hanzaki, H. Abedi, On the recrystallization behavior of homogenized AZ81 magnesium alloy: The effect of mechanical twins and $\gamma$ precipitates, Materials Science and Engineering: A 558 (2012) 44-51. 
[19] T. Li, K. Zhang, X. Li, Z. Du, Y. Li, M. Ma, G. Shi, Dynamic precipitation during multi-axial forging of an Mg-7Gd-5Y-1Nd-0.5Zr alloy, Journal of Magnesium and Alloys 1(1) (2013) 47-53.

[20] L. Jiang, J.J. Jonas, A.A. Luo, A.K. Sachdev, S. Godet, Influence of $\{10-12\}$ extension twinning on the flow behavior of AZ31 Mg alloy, Materials Science and Engineering: A 445-446 (2007) 302-309.

[21] S. Mu, J.J. Jonas, G. Gottstein, Variant selection of primary, secondary and tertiary twins in a deformed Mg alloy, Acta Materialia 60(5) (2012) 2043-2053.

[22] M.R. Barnett, Z. Keshavarz, A.G. Beer, D. Atwell, Influence of grain size on the compressive deformation of wrought Mg-3Al-1Zn, Acta Materialia 52(17) (2004) 5093-5103.

[23] X. Liu, J.J. Jonas, L.X. Li, B.W. Zhu, Flow softening, twinning and dynamic recrystallization in AZ31 magnesium, Materials Science and Engineering: A 583 (2013) 242-253.

[24] M.T. Tucker, M.F. Horstemeyer, P.M. Gullett, H. El Kadiri, W.R. Whittington, Anisotropic effects on the strain rate dependence of a wrought magnesium alloy, Scripta Materialia 60(3) (2009) 182-185.

[25] H. Watanabe, K. Ishikawa, Effect of texture on high temperature deformation behavior at high strain rates in a Mg-3Al-1Zn alloy, Materials Science and Engineering: A 523(1-2) (2009) 304-311.

[26] W. Cheng, Q. Tian, H. Yu, B.S. You, H. Wang, Optimum parameters and kinetic analysis for hot working of a homogenized Mg-8Sn-1Al-1Zn alloy, Materials \& Design 85 (2015) 762-770.

[27] K.D. Molodov, T. Al-Samman, D.A. Molodov, Profuse slip transmission across twin boundaries in magnesium, Acta Materialia 124 (2017) 397-409.

[28] M. Saadati, R.A. Khosroshahi, G. Ebrahimi, M. Jahazi, Formation of precipitates in parallel arrays on LPSO structures during hot deformation of GZ41K magnesium alloy, Materials Characterization 131 (2017) 234-243.

[29] C. Xu, M.Y. Zheng, K. Wu, E.D. Wang, G.H. Fan, S.W. Xu, S. Kamado, X.D. Liu, G.J. Wang, X.Y. Lv, Influence of rolling temperature on the microstructure and mechanical properties of $\mathrm{Mg}-\mathrm{Gd}-\mathrm{Y}-\mathrm{Zn}-\mathrm{Zr}$ alloy sheets, Materials Science and Engineering: A 559(0) (2013) 615-622.

[30] C. Lv, T. Liu, D. Liu, S. Jiang, W. Zeng, Effect of heat treatment on tension-compression yield asymmetry of AZ80 magnesium alloy, Materials \& Design 33 (2012) 529-533.

[31] Z.Z. Peng, X.H. Shao, Q.Q. Jin, C.H. Li, X.L. Ma, Deformation induced precipitation of nano-particles in an Mg88Co5Y7 alloy, Scripta Materialia 116 (2016) 57-61.

[32] M. Militzer, W.P. Sun, J.J. Jonas, Modelling the effect of deformation-induced vacancies on segregation and precipitation, Acta Metallurgica et Materialia 42(1) (1994) 133-141.

[33] V. Rothová, J. Buršík, Anomalous diffusion in presence of twin boundaries, Journal of Physics and Chemistry of Solids 68(5-6) (2007) 785-790.

[34] I. Sakaguchi, H. Haneda, Oxygen Tracer Diffusion in Single-Crystal CaTiO3, Journal of Solid State Chemistry 124(1) (1996) 195-197.

[35] L.M. Brown, G.R. Woolhouse, The loss of coherency of precipitates and the generation of dislocations, Philosophical Magazine 21(170) (1970) 329-345.

[36] S. Farjami, K. Hiraga, H. Kubo, Crystallography and elastic energy analysis of VN precipitates in FeMn-Si-Cr shape memory alloys, Acta Materialia 53(2) (2005) 419-431.

[37] P.G. McCormigk, A model for the Portevin-Le Chatelier effect in substitutional alloys, Acta Metallurgica 20(3) (1972) 351-354.

[38] J. Geiger, A. Roósz, P. Barkóczy, Simulation of grain coarsening in two dimensions by cellularautomaton, Acta Materialia 49(4) (2001) 623-629.

[39] Y. Wang, L.Q. Chen, Z.K. Liu, S.N. Mathaudhu, First-principles calculations of twin-boundary and stacking-fault energies in magnesium, Scripta Materialia 62(9) (2010) 646-649.

[40] M.H. Yoo, J.R. Morris, K.M. Ho, S.R. Agnew, Nonbasal deformation modes of HCP metals and alloys: Role of dislocation source and mobility, Metallurgical and Materials Transactions A 33(3) (2002) 813-822. [41] M. Yuasa, D. Nishihara, M. Mabuchi, Y. Chino, Hydrogen embrittlement in a magnesium grain boundary: a first-principles study, Journal of Physics: Condensed Matter 24(8) (2012) 085701. 
[42] J.W. Martin, Precipitation hardening: theory and applications, Butterworth-Heinemann2012.

[43] D.A. Porter, K.E. Easterling, M. Sherif, Phase Transformations in Metals and Alloys, (Revised Reprint), CRC press2009.

[44] F.R.N. Nabarro, J.P. Hirth, Dislocations in Solids, Elsevier Science2007.

[45] J. Jiang, M. Song, H. Yan, C. Yang, S. Ni, Deformation induced dynamic recrystallization and precipitation strengthening in an MgZnMn alloy processed by high strain rate rolling, Materials Characterization 121 (2016) 135-138. 

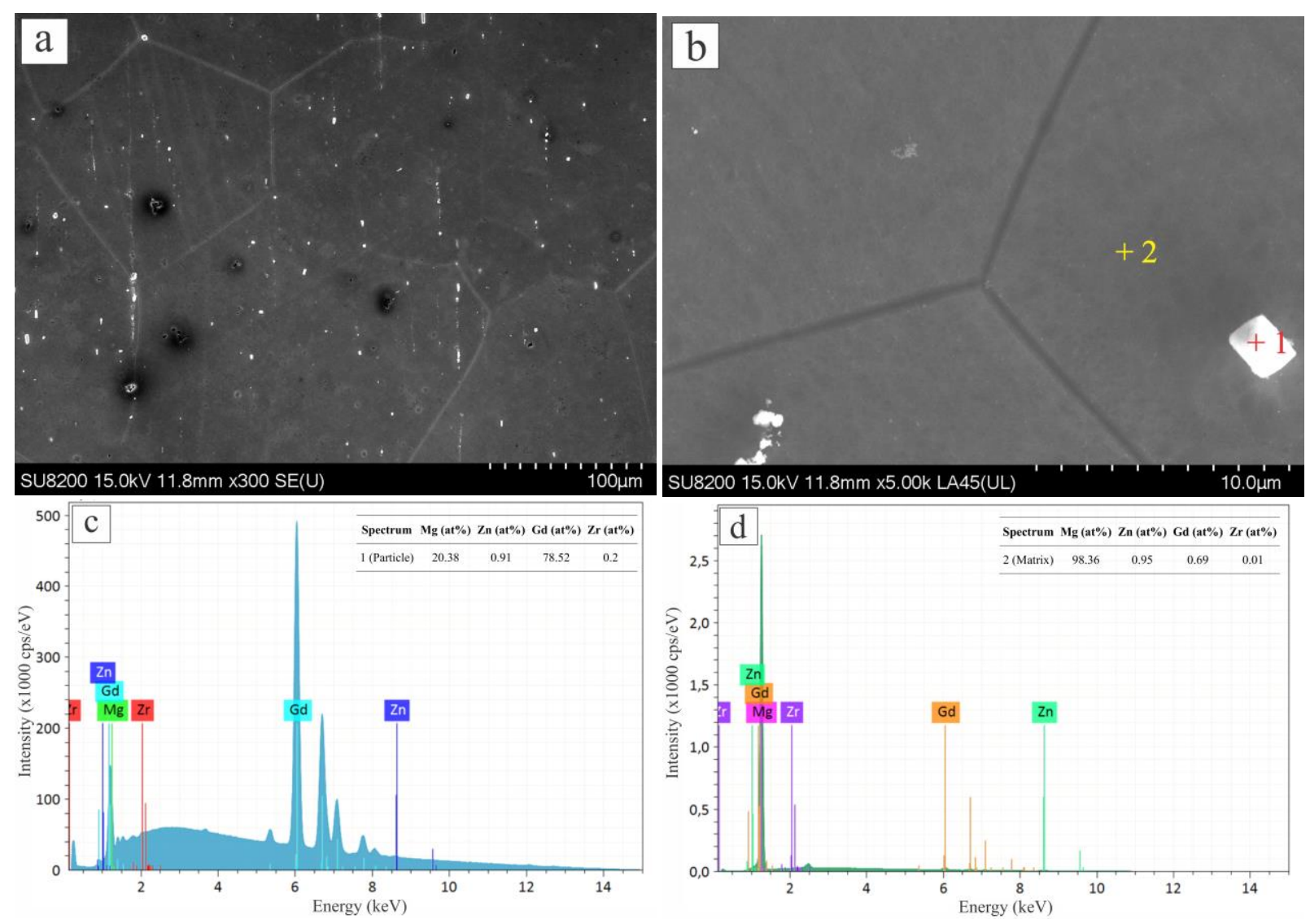

Fig.1. SEM micrographs of the solutionized $\mathrm{Mg}-3.5 \mathrm{Gd}-1 \mathrm{Zn}-0.6 \mathrm{Zr}$ alloy at $540^{\circ} \mathrm{C}$ for $3 \mathrm{hr}$, a) contains $\mathrm{MgGd}_{3}$ particles distributed within the equiaxed grains in previous extrusion direction. b) blocky-shaped $\mathrm{MgGd}_{3}$ particle, c) EDS spectra of the $\mathrm{MgGd}_{3}$ particle (point1) in (b), d) EDS spectra of the matrix (point2) in (b). 

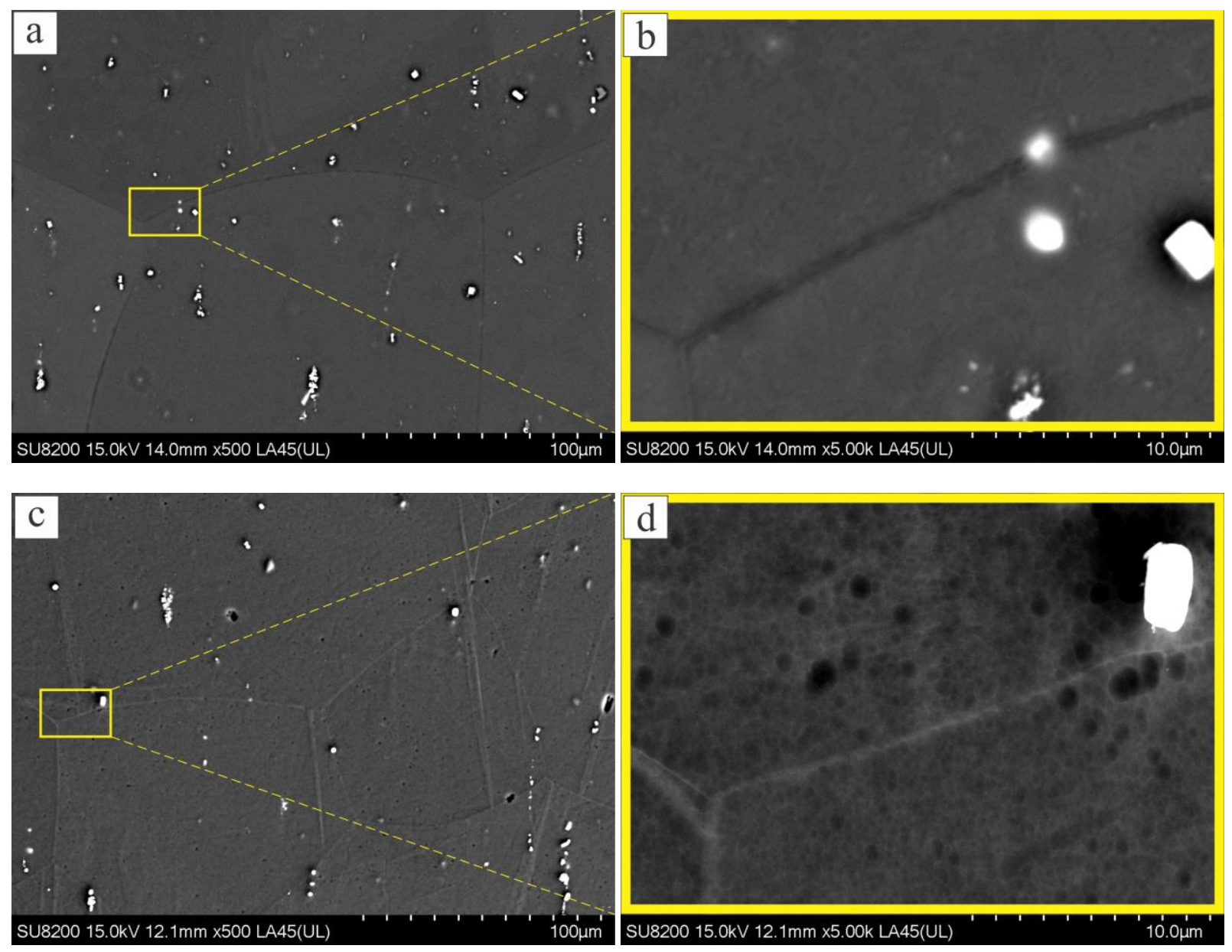

Fig. 2. Precipitate-free microstructures of the $\mathrm{Mg}-3.5 \mathrm{Gd}-1 \mathrm{Zn}-0.6 \mathrm{Zr}$ alloy after 5 min holding at a,b) $350^{\circ} \mathrm{C}$ and c,d) $450^{\circ} \mathrm{C}$. 

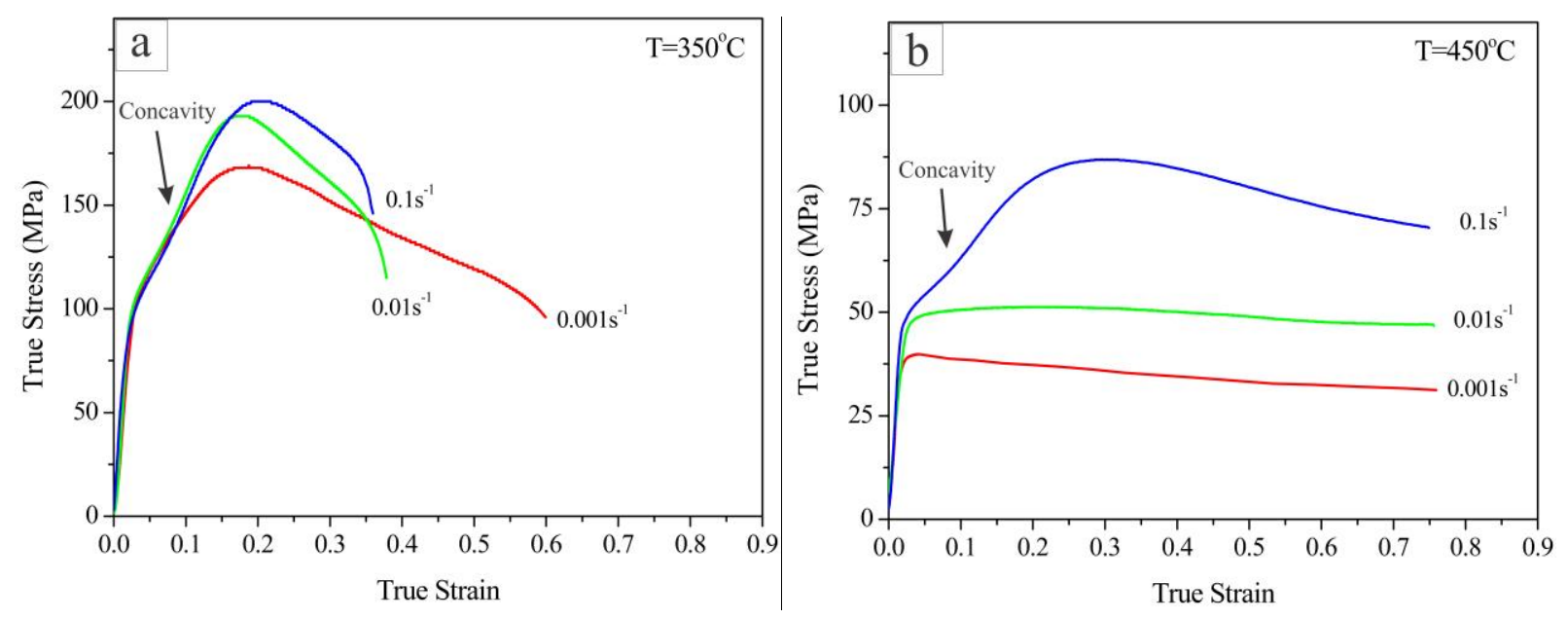

Fig.3. Flow stress curves of the solutionized Mg-3.5Gd-1Zn-0.6Zr alloy during hot compression at the strain rates of 0.001 to $0.1 \mathrm{~s}^{-1}$ and at the deformation temperature of a) $350^{\circ} \mathrm{C}$ and b) $450^{\circ} \mathrm{C}$. 


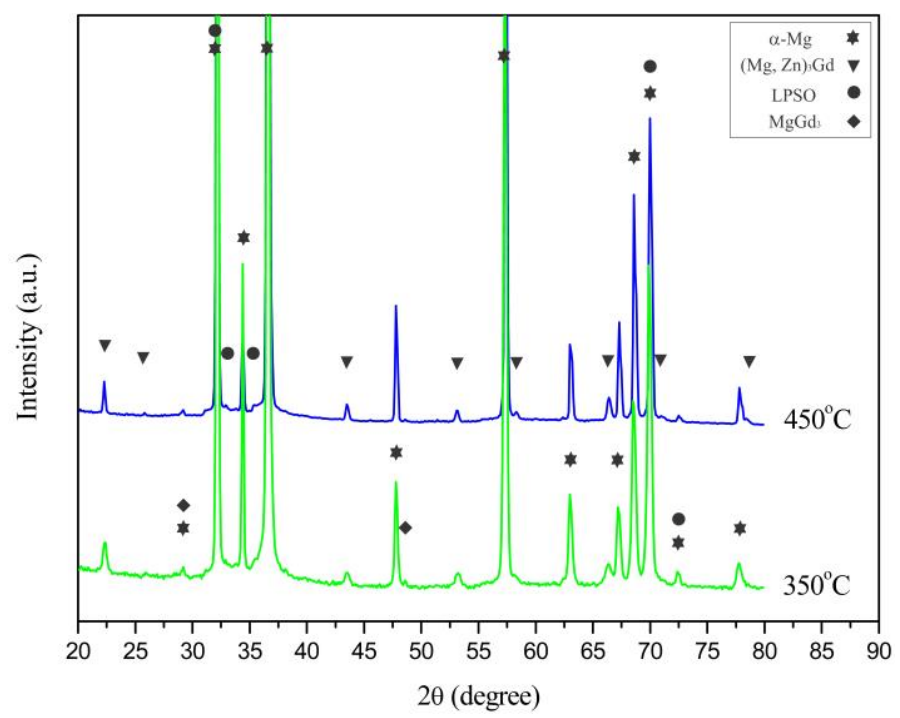

Fig.4. X-ray diffraction patterns of $\mathrm{Mg}-3.5 \mathrm{Gd}-1 \mathrm{Zn}-0.6 \mathrm{Zr}$ alloy after deformation at $350^{\circ} \mathrm{C}$ and $450^{\circ} \mathrm{C}$ and the strain rate of $10^{-3} \mathrm{~s}^{-1}$. 

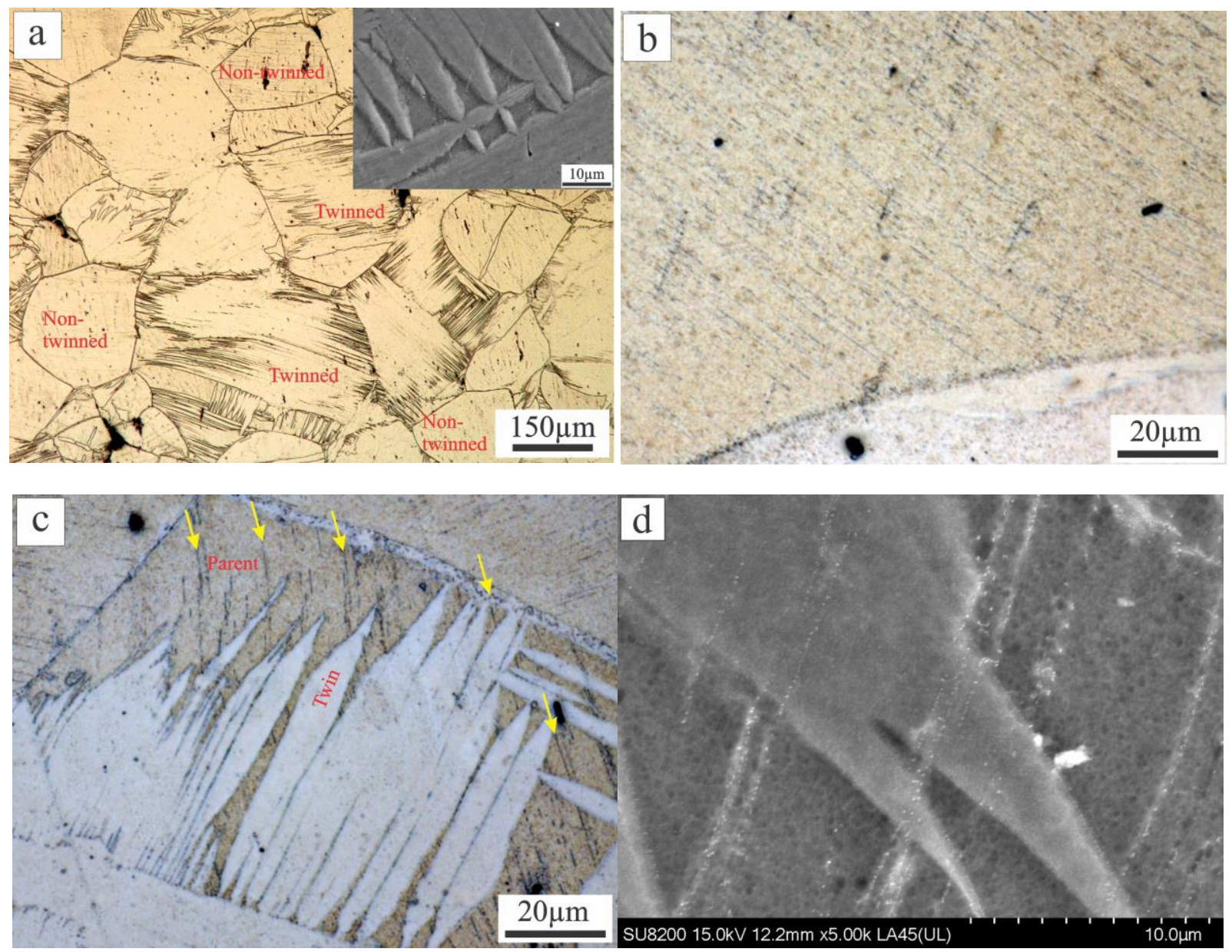

Fig. 5. Micrographs of $\mathrm{Mg}-3.5 \mathrm{Gd}-1 \mathrm{Zn}-0.6 \mathrm{Zr}$ alloy after deformation at $350^{\circ} \mathrm{C}$ and the strain rate of $0.001 \mathrm{~s}^{-1}$. a)

Twinned and non-twinned grains and the intersecting twins in the inset, b) parallel precipitate lines in the nontwinned grain, c) parallel precipitate lines in the parent region of the twinned grain; d) intersection of twins and precipitate lines in higher magnification. 

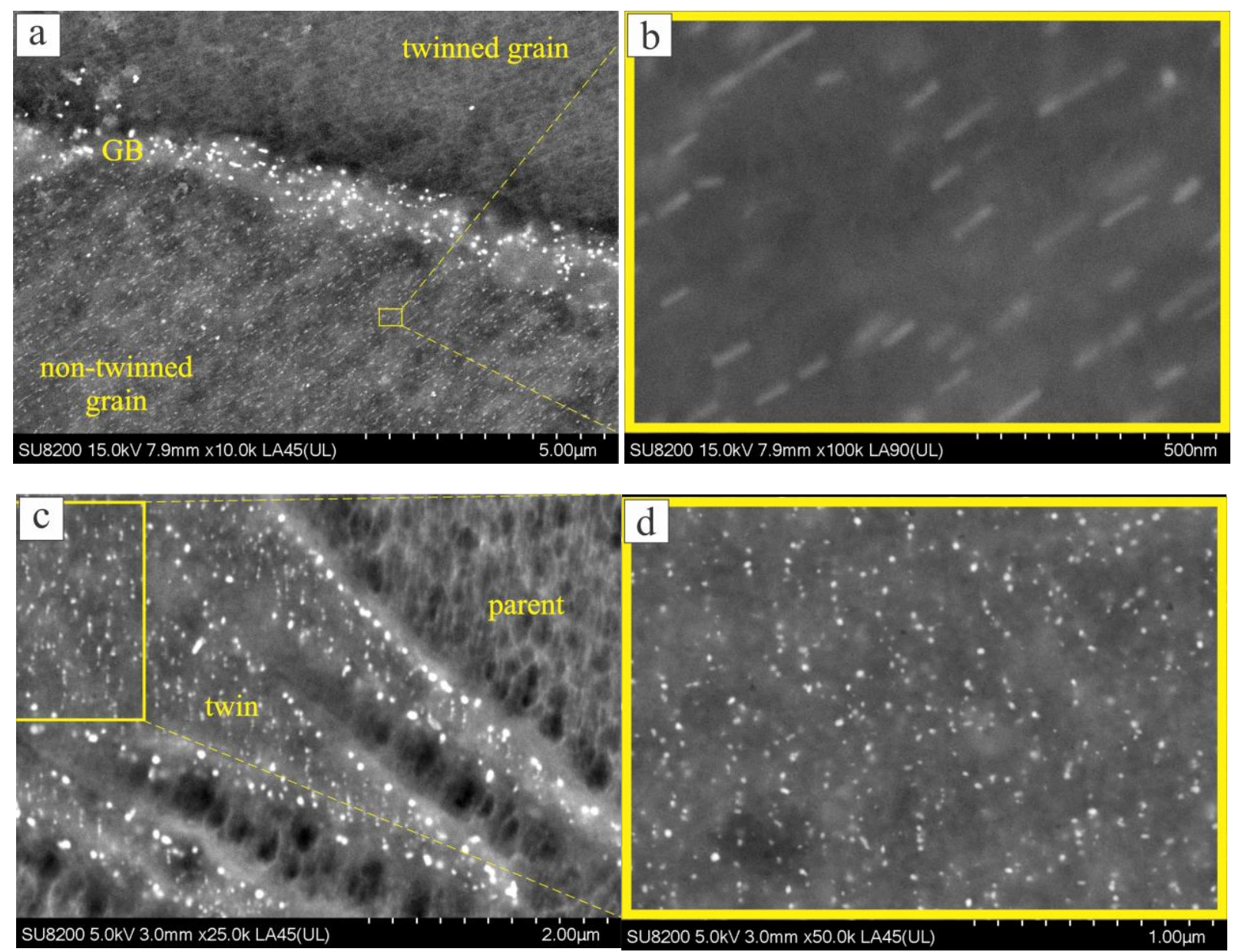

Fig. 6. Dynamic precipitation in $\mathrm{Mg}-3.5 \mathrm{Gd}-1 \mathrm{Zn}-0.6 \mathrm{Zr}$ alloy during deformation at $350^{\circ} \mathrm{C}$ and the strain rate of $0.001 \mathrm{~s}^{-1} \mathrm{a}$ ) twinned and non-twinned grains with spherical precipitates at grain boundary and rod-shape precipitates in non-twinned grain; b) rod-shape precipitates in higher magnification, c) precipitation within twins of the twinned grain with spherical shape; d) the spherical precipitates of twin interior in higher magnification. 

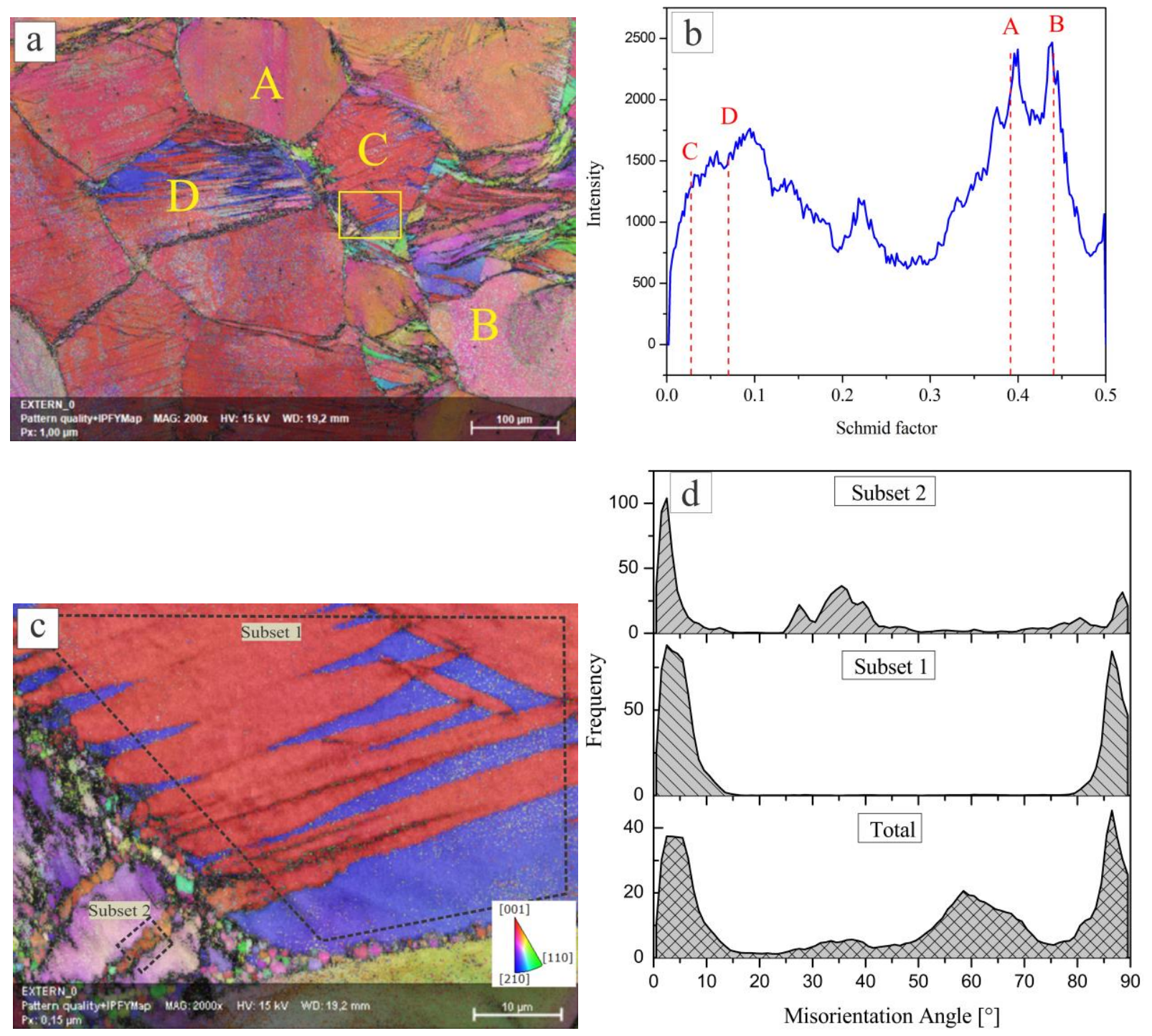

Fig. 7. EBSD analysis of $\mathrm{Mg}-3.5 \mathrm{Gd}-1 \mathrm{Zn}-0.6 \mathrm{Zr}$ alloy deformed at of $350^{\circ} \mathrm{C}$ and the strain rate of $0.001 \mathrm{~s}^{-1}$; a) image quality + orientation map of twinned and non-twinned grains; b) variations in Schmidt factor of Fig. a for $\{0001\}\langle 11 \overline{2} 0\rangle$ basal slip system; c) orientation map of the selected zone in Fig.5a with smaller pixel size; d) distribution of misorientation angle for the total area, subset 1 and subset 2 of Fig. 5c. 

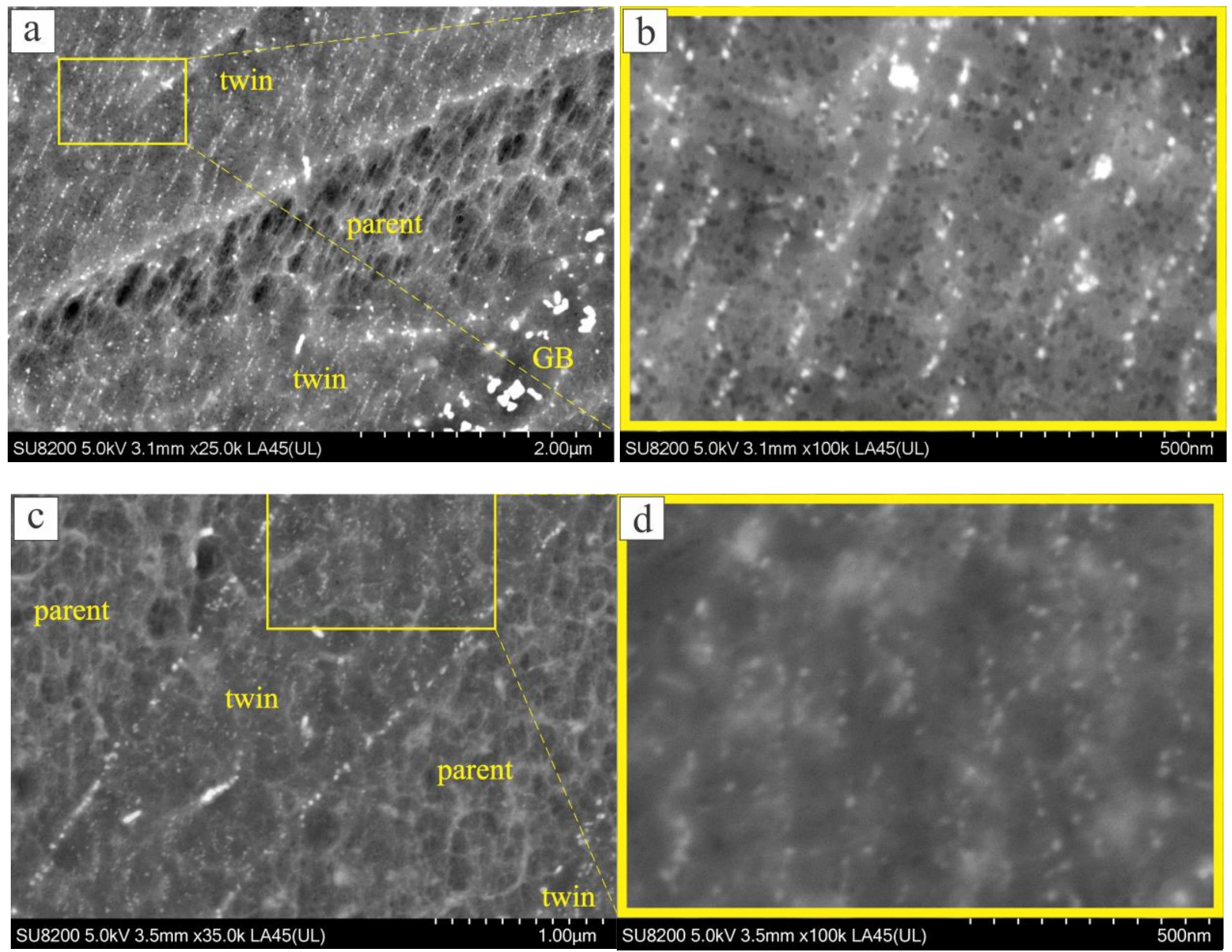

Fig. 8. Microstructure of the $\mathrm{Mg}-3.5 \mathrm{Gd}-1 \mathrm{Zn}-0.6 \mathrm{Zr}$ alloy deformed at $350^{\circ} \mathrm{C}$ and a,b) the strain rates of $0.01 \mathrm{~s}^{-1}$, showing the spherical precipitates which are mostly localized at twinned region of the grain, c,d) the strain rates of $0.1 \mathrm{~s}^{-1}$ with similar behavior to the lower strain rates with a suppressed precipitation. 

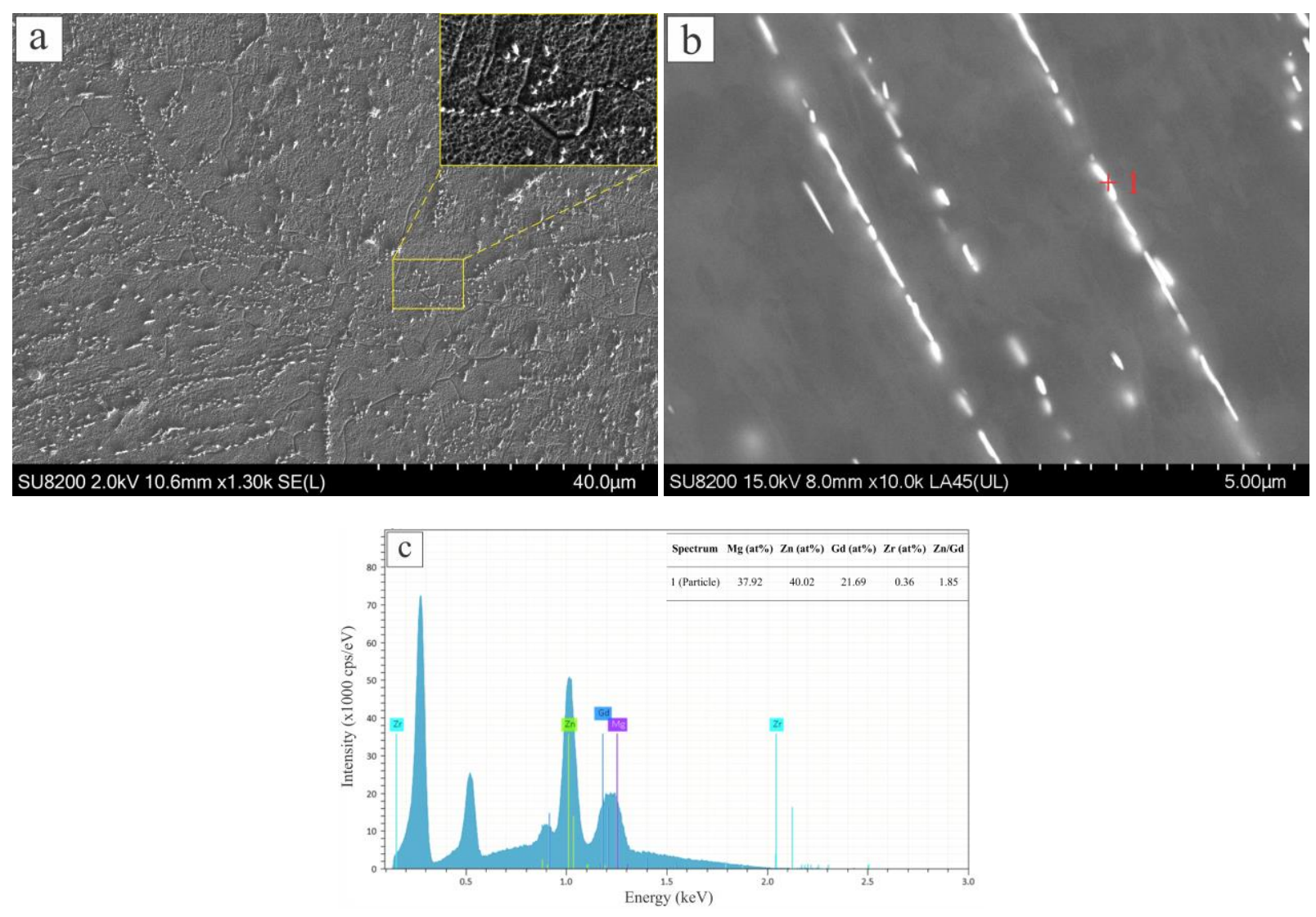

Fig. 9. Microstructures of the $\mathrm{Mg}-3.5 \mathrm{Gd}-1 \mathrm{Zn}-0.6 \mathrm{Zr}$ alloy deformed at $450^{\circ} \mathrm{C}$ and strain rates of $0.001 \mathrm{~s}^{-1}$ : a) decorated initial boundaries with the precipitation of the $(\mathrm{Mg}, \mathrm{Zn})_{3} \mathrm{Gd}$ phase as well as the DRXed grains around the initial boundaries, b) intragranular rod-shaped precipitates in parallel lines, c) EDS spectra of the (Mg, $\mathrm{Zn})_{3} \mathrm{Gd}$ precipitates. 


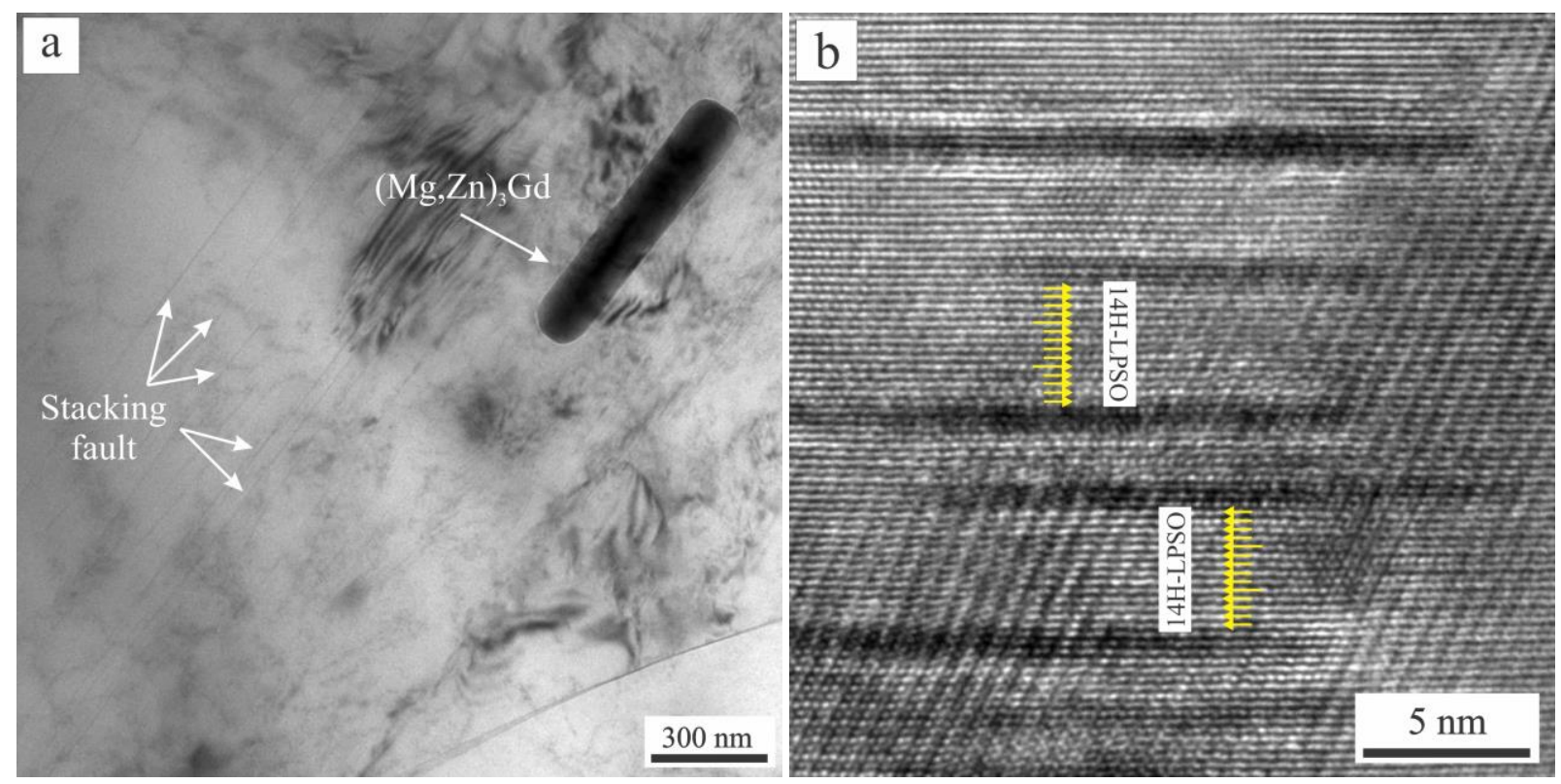

Fig. 10. a) TEM image of the $(\mathrm{Mg}, \mathrm{Zn})_{3} \mathrm{Gd}$ precipitates aligned with the stacking faults of the LPSO structure, b) HRTEM image of the $14 \mathrm{H}-\mathrm{LPSO}$ structure in hot compressed $\mathrm{Mg}-3.5 \mathrm{Gd}-1 \mathrm{Zn}-0.6 \mathrm{Zr}$ magnesium alloy at $450^{\circ} \mathrm{C}$ and the strain rate of $0.001 \mathrm{~s}^{-1}$. 

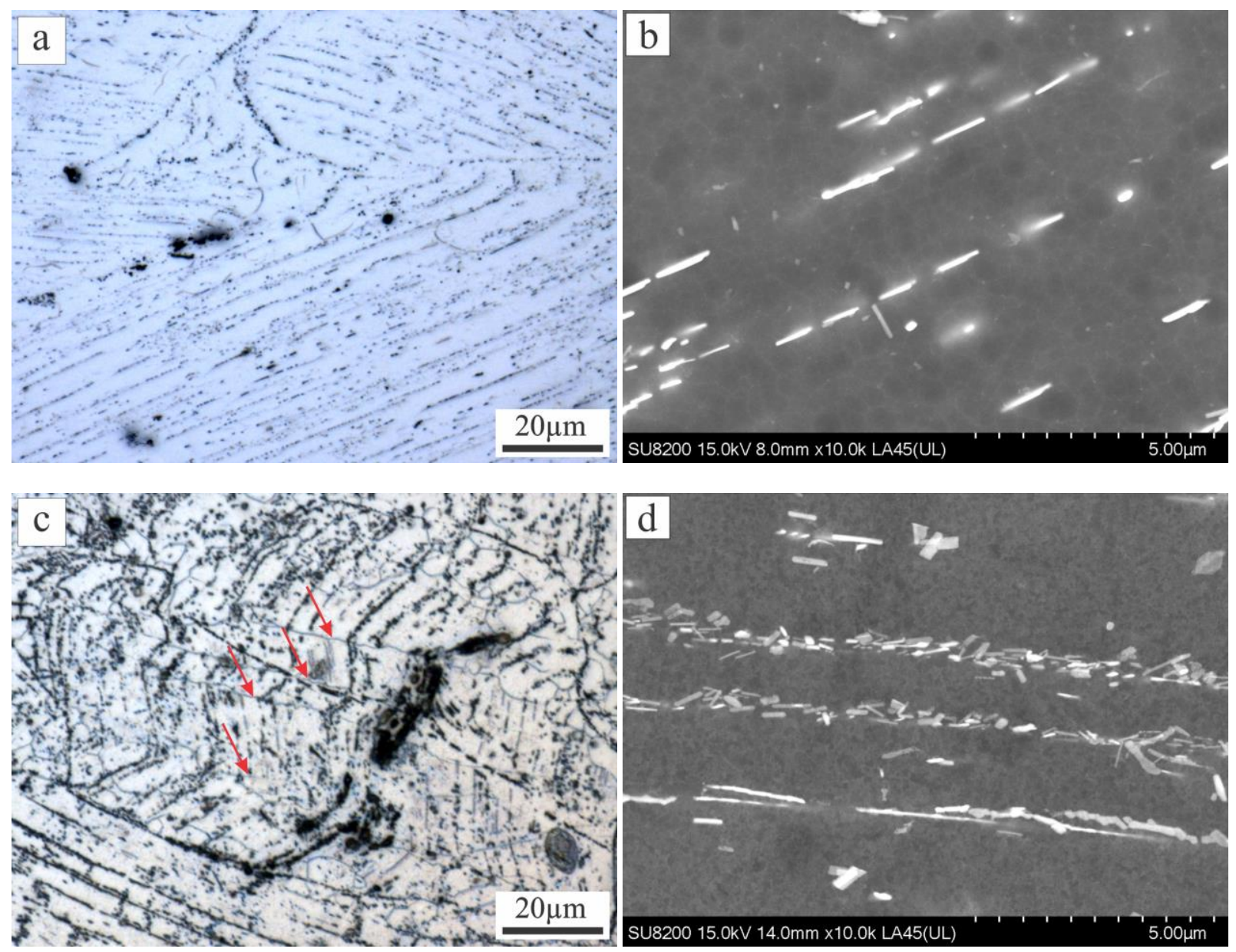

Fig. 11. Microstructures of the $\mathrm{Mg}-3.5 \mathrm{Gd}-1 \mathrm{Zn}-0.6 \mathrm{Zr}$ alloy deformed at $450^{\circ} \mathrm{C}$ and a,b) strain rates of $0.01 \mathrm{~s}^{-1}$ showing the rod-shape precipitates in parallel arrays, c,d) strain rates of $0.1 \mathrm{~s}^{-1}$. Twins are pointed by arrows in Fig. $\mathrm{c}$ and precipitate length is decreased with increase in the strain rate. 


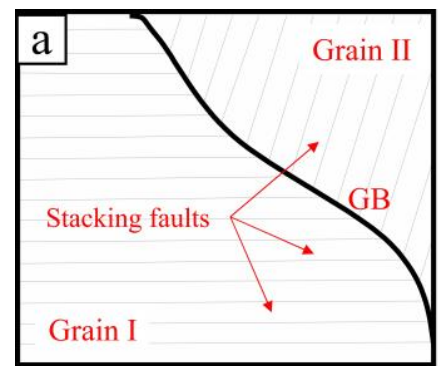

Initial state: SSS state

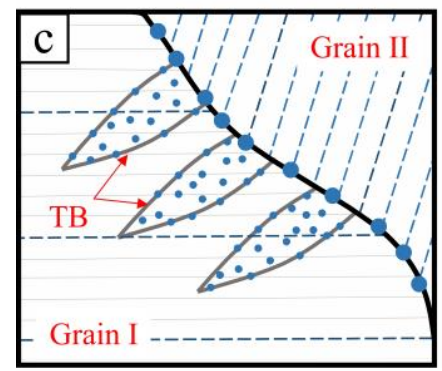

$\varepsilon_{2}\left(>\varepsilon_{1}\right)$

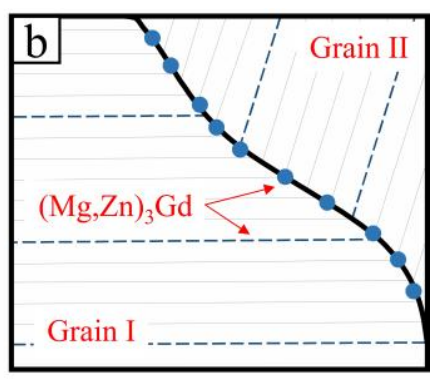

Hot compression: $\left(\varepsilon_{1}\right)$

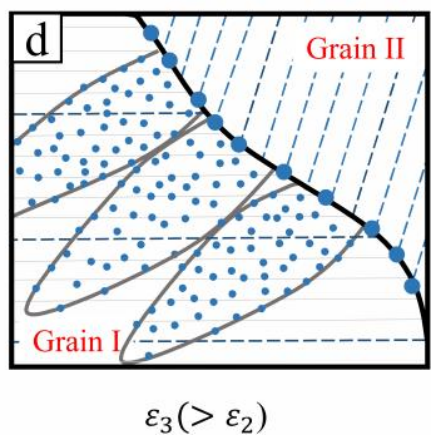

Fig. 12. Schematic representation of the twin-assisted precipitation mechanism; a) the precipitate-free matrix in the super saturated solid solution state containing solute-enriched stacking faults, proceeding hot compression leads to b) $(\mathrm{Mg}, \mathrm{Zn})_{3} \mathrm{Gd}$ precipitation on some stacking faults and slip bands of grains, c) twinning at low Schmid factor grains and slip at high Schmid factor grains d) precipitation on moving twin boundaries during twin growth. 